\title{
APERT SYNDROME (ACROCEPHALO SYNDACTYLY): A RARE BUT RECOGNIZABLE HUMAN MALFORMATION SYNDROME
}

\author{
P. Ramu1, R. Bhavani Shankar², A. Deepak Kumar³
}

\section{HOW TO CITE THIS ARTICLE:}

P. Ramu, R. Bhavani Shankar, A. Deepak Kumar. "Apert Syndrome (Acrocephalo Syndactyly): A Rare but Recognizable Human Malformation Syndrome". Journal of Evolution of Medical and Dental Sciences 2015; Vol. 4, Issue 12, February 09; Page: 2072-2075, DOI: 10.14260/jemds/2015/297

ABSTRACT: BACKGROUND: Apert syndrome is a rare autosomal dominant Mendelian disorder characterized by a set of recognizable patterns of human malformations, having paediatric, plastic surgical, Ortholpaedic and Dental implications requiring early recognition \& effective management strategies for good Cosmetic and functional out-come.

KEYWORDS: Apert Syndrome, Acrocephalosyndactyly, Craniosynostosis.

Case Characteristics: A 2 Years and 4 months - female child admitted for simple febrile seizures and found to be dysmorphic.

OBSERVATIONS: The Child was first born to nonconsanguinous parents, (mother age 25 Years and father age 28 Years) brought for Fever, Cold, Cough of one day duration and 1 episode of seizure (simple febrile seizures) following upper respiratory tract infection and found to have mental retardation, Brachycephaly, Craniosynostosis, hypertelorism, midfacial hypoplasia, shallow orbits, mitten hands, syndactyly of both feet and palms (osseous and cutaneous)

DISCUSSION: Apert Syndrome (Acrocephalosyndactyly) was reported by Wheaton in 1894. ${ }^{1}$ In 1906 , Apert summarized nine cases. ${ }^{2}$ By 1960, Blank noted the recording of 150 cases. $^{3}$ The incidence was expected to vary greatly with estimates of 1:60,000 live births to 1 : in 2,00,000 live births as suggested by different studies. Males and females are affected equally. The Syndrome is characterized by more frequent abnormalities includes mental deficiency may be present (but normal intelligence has been observed) Craniofacial abnormalities (like Craniosynostosis, Flat facies, shallow orbits, hypertelorism, strabismus, maxillary hpoplasia, Small nose, Narrow palate with or without cleft palate, Pseudomandibular progranathism and crowding of teeth). Limb defects (like Osseous and/ or cutaneious syndactyly, varying from total fusion to partial fusion most commonly with complete fusionof second, third, and fourth fingers. Distal phalanges of the thumbs are often broad and in valgus position. Fingers may be short. Cutaneious syndactyly of all toes with or without osseous syndactyly. Distal hallux may be broad and malformed) and Skin changes (like a Moderate to severe acne, including the forearms at adolescence).

Occasional Abnormalities (like short humerus, Pyloric stenosis, ventricular septal defect, polycystic kidney and bicornuate uterus).

DIFFERENTIAL DIAGNOSIS: Includes all other syndromes characterized by Acrocephalosyndactyly such as 1) crouzon syndrome 2) carpenter syndrome 3) Pfeiffer syndrome.

The hands in patients with Apert syndrome always show four common features 4

1. A short thumb with radial deviation. 


\section{CASE REPORT}

2. Complex syndactyly of the index, long and ring finger.

3. Symbrachyphalangism.

4. Simple syndactyly of the fourth webspaace.

Based on the first webspace, we can differentiate three different types of hand deformation. The typical hand deformities in patients with Apert syndrome distinguish it from the other syndromes. ${ }^{5}$

\begin{tabular}{|c|c|c|c|}
\hline $\begin{array}{c}\text { First } \\
\text { webspace }\end{array}$ & Type I ("spade") & Type II ("mitten") & Type III ("rosebud") \\
\hline $\begin{array}{c}\text { Middle three } \\
\text { fingers }\end{array}$ & $\begin{array}{c}\text { Side -toside fusion } \\
\text { with flat palm }\end{array}$ & $\begin{array}{c}\text { Fusion of fingertops } \\
\text { forming a concave palm }\end{array}$ & $\begin{array}{c}\text { Tight fusion of all digits with } \\
\text { one conjoined nail }\end{array}$ \\
\hline $\begin{array}{c}\text { Fourth } \\
\text { webspace }\end{array}$ & $\begin{array}{c}\text { Simple and } \\
\text { incomplete } \\
\text { syndactyly }\end{array}$ & $\begin{array}{c}\text { Simple and complete } \\
\text { syndactyly }\end{array}$ & $\begin{array}{c}\text { Simple and complete } \\
\text { syndactyly }\end{array}$ \\
\hline
\end{tabular}

Natural History Etiology: Autosomal dominant, with the vast majority of cases representing a fresh mutation. ${ }^{6}$ One factor in the sporadic cases has been older paternal age. The recurrence risk for the unaffected parents of a child with Apert syndrome is negligible, whereas the recurrence risk for the offspring of the affected individual is 50 per cent.

There are no adequate data on the long term follow up of patients. Early surgery for craniosynostosis, however, would seem indicated when the condition is of sufficient magnitude to give rise to increased intracranial pressure. Though there can be mental deficiency in patients who have no evidence of increased intracranial pressure, it is an irregular occurrence. There should be vigorous early management of the syndrome. When the thumb is immobilized, early surgery to allow for a pincer grasp is indicated, with later attempts at further improvement of hand function. Newer Plastic oral and maxillofacial (OMS) re- constructive surgical techniques may allow for improved facial cosmetic reconstruction as well as functional outcome of hand performance.

Therefore, every neonate suspected of having Apert syndrome deserves a complete evaluation for other malformations as well as referred to appropriate surgical faculties for improved cosmetic and functional outcome.

\section{REFERENCES:}

1. Wheaton, S.W: Two specimens of congenital cranial deformity ininfants associated with fusion of the fingers and toes. Trans. Path. Soc. London, 45: 238, 1894.

2. Apert, E De 1 Acrocephalosyndactylie. Bull. Soc. Med., 23:1310 1906.

3. Blank, C.E. Aperts syndrome (a type of acrocephalo-syndactyly). Observations on British series of thirty nine cases. Ann Hum. Genet., 24:151,1960.

4. Upton, J (April 1991). "Apert Syndrome. Classification and pathologic anatomy of limb anomalies". Clinics in plastic surgery 18(2): 321-55. ISSN 0094-1298.

(https:www.worldcat.org/issn/0094-1298).PMID 2065493

(https://www.ncbi.nlm.nih.gov/pubmed/2065493). 


\section{CASE REPORT}

5. Kaplan, LC (April 1991). “Clinical assessment and multispecialty management of Apert syndrome". Clinics in plastic surgery 18(2):217-25 ISSN 0094-1298.

(https://www.worldcat.org/issn/0094-1298).PMID 2065483.

(https://www.ncbi,nlm.nih.gov/;ubmed/2065483).

6. Cohen, M.M.: An etiologic and nosologic overview of craniosynosrtosis syndromes. Birth Defects Original Article Series. 11:137, 1975.

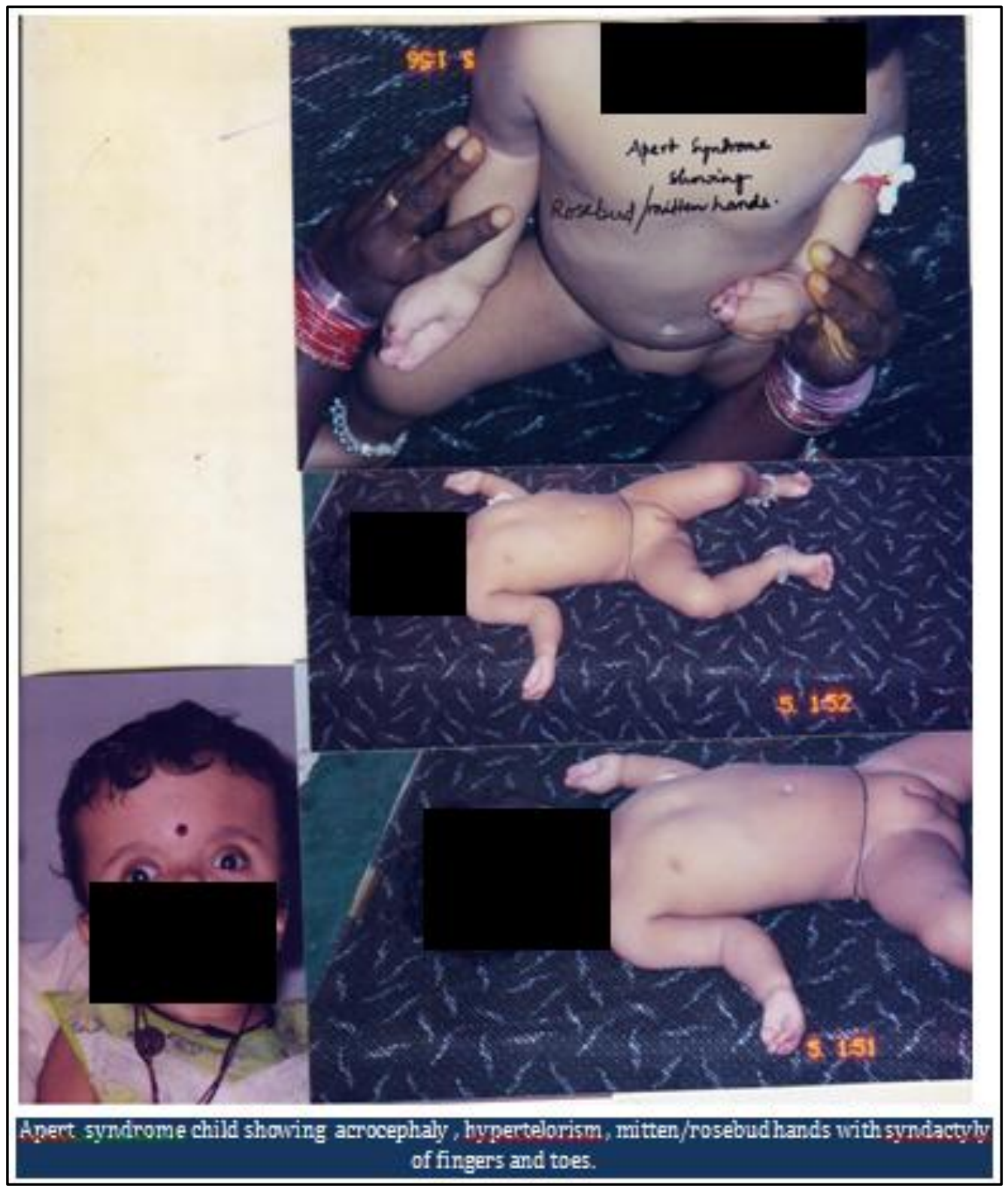




\section{AUTHORS:}

1. P. Ramu

2. R. Bhavani Shankar

3. A. Deepak Kumar

\section{PARTICULARS OF CONTRIBUTORS:}

1. Assistant Professor, Department of Paediatrics, Andhra Medical College, King George Hospital, Visakhapatnam.

2. Former Assistant Professor, Department of Paediatrics, Andhra Medical College, King George Hospital, Visakhapatnam.

3. Assistant Professor, Department of Paediatrics, Andhra Medical College, King George Hospital, Visakhapatnam.

\section{NAME ADDRESS EMAIL ID OF THE CORRESPONDING AUTHOR:}

Dr. P. Ramu, \# 14-1-122/13, FF-3,

Rajasagi Residency, Nowroji Road, Maharanipeta, Visakhapatnam,

Andhra Pradesh-530002.

E-mail: drpramu73@gmail.com

Date of Submission: 08/01/2015.

Date of Peer Review: 09/01/2015.

Date of Acceptance: 31/01/2015.

Date of Publishing: 09/02/2015. 